\title{
Pengaruh Orientasi Kewirausahaan Dan Orientasi Pasar Terhadap Kinerja Umkm Pada Bidang Kuliner Di Pasar Lama Tangerang
}

\author{
Andri Prasetyo dan Andi Wijaya \\ Program Studi S1 Manajemen Fakultas Ekonomi Universitas Tarumanagara, Jakarta \\ Email: andri.prasetyo0805@gmail.com
}

\begin{abstract}
The purpose of this study was to find out 1) whether entrepreneurial orientation had a significant effect and positively related to the performance of MSMEs in the culinary field in Tangerang Old Market, 2) whether market orientation had a significant effect and positively related to the performance of MSMEs in the culinary field at Tangerang Lama Market. The population in this study is Micro, Small and Medium Enterprises in Tangerang. The sample used in this study was 50 respondents of UMKM owners in the culinary field at Tangerang Old Market. The sampling technique used was nonprobability sample with purposive sampling sampling method. Overall the results of this study, namely 1) entrepreneurial orientation have a significant effect and positively related to the performance of MSMEs in the culinary field in Tangerang Old Market, 2) market orientation has a significant effect and positively related to the performance of MSMEs in the culinary field at Tangerang Old Market.
\end{abstract}

Keywords: entrepreneurial orientation, market orientation, performance.

\begin{abstract}
Abstrak: Tujuan penelitian ini adalah untuk mengetahui 1) apakah orientasi kewirausahaan berpengaruh signifikan dan berhubungan positif terhadap kinerja UMKM pada bidang kuliner di Pasar Lama Tangerang, 2) apakah orientasi pasar berpengaruh signifikan dan berhubungan positif terhadap kinerja UMKM pada bidang kuliner di Pasar Lama Tangerang. Populasi dalam penelitian ini adalah Usaha Mikro Kecil dan Menengah di Tangerang. Sampel yang digunakan pada penelitian ini yaitu 50 reponden pemilik UMKM pada bidang kuliner di Pasar Lama Tangerang. Teknik pengambilan sampel yang digunakan yaitu nonprobability sample dengan metode pengambilan sampel purposive sampling. Secara keseluruhan hasil dari penelitian ini yaitu 1) orientasi kewirausahaan berpengaruh signifikan dan berhubungan positif terhadap kinerja UMKM pada bidang kuliner di Pasar Lama Tangerang, 2) orientasi pasar berpengaruh signifikan dan berhubungan positif terhadap kinerja UMKM pada bidang kuliner di Pasar Lama Tangerang.
\end{abstract}

Kata kunci: orientasi kewirausahaan, orientasi pasar, kinerja.

\section{LATAR BELAKANG}

Seiring dengan perkem bangan zaman yang pesat kemajuan dalam sektor perekonomian yang semakin meningkat tinggi dan penuh persaingan. Membuat dunia bisnis wisata kuliner pada saat ini dituntut untuk melakukan langkah-langkah yang sangat strategis untuk dapat bersaing khususnya pada Usaha Mikro Kecil dan Menengah (UMKM).Usaha Mikro Kecil dan Menengah (UMKM) mempunyai lingkungan bisnis yang sangat dinamis dan penuh ketidakpastian (seperti supplier, customer, dan pesaing). Usaha Mikro Kecil dan Menengah (UMKM) adalah usaha rakyat yang pada saat ini mendapat perhatian dan keistimewaan lebih yang dilindungi oleh Undang-undang, dan 
mendapatkan bantuan kredit usaha dengan bunga rendah, kemudahan persyaratan izin usaha, bantuan pengembangan usaha dari lembaga pemerintah, serta beberapa kemudahan lainnya. UU No. 20 Tahun 2008 merupakan peraturan yang mengatur mengenai kriteria Usaha Mikro Kecil dan Menengah (UMKM) di Indonesia. Usaha Mikro Kecil dan Menengah (UMKM) merupakan salah satu tulang punggung ekonomi disuatu negara. Didalam perekonomian Indonesia Usaha Mikro Kecil dan Menengah (UMKM) merupakan suatu kelompok usaha yang memikliki jumlah yang sangat besar. Selain itu kelompok ini juga terbukti tahan dari berbagai macam goncangan krisis ekonomi. Maka sudah menjadi keharusan penguatan didalam kelompok Usaha Mikro Kecil dan Menengah (UMKM) yang melibatkan banyak kelompok. Usaha Mikro Kecil dan Menengah (UMKM) juga menjadi salah penyumbang yang sangat besar bagi tenaga kerja maupun Produk Domestik Bruto (PDB). Dikutip dari (CNN Indonesia, 2016), kontribusi sektor UMKM terhadap produk domestik bruto (PDB) meningkatdari 57.84\% menjadi 60.34\%. Tak hanya itu, disektor UMKM juga telah banyak membantu penyerapan tenaga kerja didalam negeri. Penyerapan tenaga kerja disektor UMKM tumbuh dari 96,99\% menjadi 97,22\% terhitung dari tahun 2011. Ini menunjukkan bahwa sektor UMKM tidak boleh diabaikan. Salah satu langkah strategis dalam berbisnis yang dapat diambil Usaha Mikro Kecil dan Menengah (UMKM) adalah dengan cara meningkatkan kinerja usaha suatu perusahaan tersebut. Meningkatkan kinerja usaha sangat diperlukan untuk dapat membuat bisnis yang baik dan dapat bersaing dengan kompetitornya.

Salah satu industri di Indonesia yang berkembang pesat pada saat ini adalah industri kuliner. Industrikuliner pada saat ini dinilai sebagai industri yang paling cepat dijalankan karena dengan modal yang cenderung kecil dan didukung dengan daya beli masyarakatyang cukup tinggi. Industri kuliner juga mencakup segmentasi pasar yang sangat luas dibanding industri lain. Pada dasarnya, makanan adalahkebutuhan semua orang. Selain itu bisnis kuliner merupakan bisnis yangpaling mudah untuk dilakukan inovasi di dalam penyajiannya. Namun kemampuan pemilik usaha dalam mengembangkan bisnis kuliner di daerah Pasar Lama Tangerang masih kurang maksimal. Hal ini dikarenakan kinerja usaha bisnis kuliner di Pasar Lama Tangerang tidak optimal. Kinerja usahasendiri merupakan faktor penting dalam menentukan suatu keberhasilan UMKM tersebut. Tingkatan kinerja usaha ini dapat dilihat dari sejauh mana UMKM ini dapat mencapai sasaran, tujuan, visi dan misi yang sudah ditetapkan. Namun dengan adanya persaingan yang ketat biasa berdampak pada penurunan kinerja usaha yang akan menghambat kemajuan dan pertumbuhan disuatu perusahaan.

Dengan melemahnya kemampuan manajerial dapat mengakibatkan pengusaha kecil tidak mampu bersaing dan tidak dapat menjalankan usahanya dengan baik dan dapat menurunkan performa pendapatan usaha tersebut (Kuncoro, 2000).Sehingga UMKM perlu memperhatikan peningkatan kinerja usaha trhadap perusahaan yang dijalankan, maka terdapat duafaktor yang telah dianggap penting yaitu orientasi kewirausahaan(Entrepreneurial Orientation)yang mempunyai lima dimensi yaitu inovasi, proaktif, pengambilan resiko, agresivitas kompetitif, dan otonomi serta orientasi pasar (Market Orientation) agar dapat mmbantu UMKM mencapai performa lebih baik (Jaworski dan Kohli, 1993). Orientasi kewirausahaan (Entrepreneurial Orientation) merupakan suatu dasar untuk mencari peluang bisnis menuju kesuksesan dan memiliki peran penting dalam meningkatkan kinerja bisnis yang baik. Orientasi kewirausahaan dapat ditentukan berdasarkan lima dimensi, yaitu inovasi, proaktif,pengambilan resiko, agresivitas kompetitif, dan otonomi. (Miller, 1983). Pertama inovasi, inovasi dilihat padakreativitasan dan eksperimentasi dalam memperkenalkan produk baru atau jasa dengan cara mengembangkan teknologi untuk mengembangkan produk baru serta melakukan pemasaran dalam periklanan dengan cara yang berbeda dengan yang lainnya,sehingga produk tersebut memiliki keunggulan tersendiri dan dapat memiliki peluang baru (Lumpkin dan Dess, 2001). Maka usaha yang tidak focus dalam pengembangan produk inovasi baru akan mengalami kesulitan dan tidak dapat memenuhi kebutuhan dan keinginan pelanggan. Oleh karena itu inovasi salah satu hal penting untuk memiliki nilai unggul dari pesaingnya. Kedua proaktif menunjukan tindakan pada suatu perusahaan dalam mencari peluang usaha untuk mengantisipasi permintaan pelangganyang akan datang dan perusahaan akan memiliki sikap proaktif agar prusahaan semakin berkembang (Hughes et al., 2007). Maka dari itulah apabila UMKM tidak menerapkan proaktif akan dapat kehilangan 
peluang-peluang usaha dan dapat diambil oleh pesaingnya.Ketiga, pengambilan resiko adalah suatu kegiatan dalam mengambil langkah yang berani tanpa pengetahuan yang pasti dan dapat menyelesaikan masalah dengan baik dan tepat.Dengan adanya pengamblan resiko yang benar maka akan dapat meningkatkan kinerja usaha dalam UMKM. (Lumpkin dan Dess, 2001; Rauch et al., 2009). Pengusaha yang tidak berani mengambil resiko dalam memasuki pasar baru akan kesulitan tidak dapat berkembang dan menghambat kinerja usaha tersebut.Keempat, agresivitas kompetitif merupakan kecenderungan UMKM untuk mencari tau cara bagaimana dapat bersaing dengan pesaingnya secara langsung.Yang bertujuan untuk memperbaiki posisi dan dapat mengunguli persaingan di pasar tersebut. Maka jika UMKM tidak mampu bersaing akan ketinggalan secara perkembangan usaha dengan pesaing lainnya. Kelima, otonomi merupakan suatu tindakan yang secara bebas dari individu atau tim dalam menyalurkan ide-ide baru dan pelaksanaannya sesuai dengan visi \& misi yang dimiliki (Lumpkin dan Dess, 1996). Maka jika UMKM tidak dapat menerima masukan dari internal maupun eksternal akan berkurangnya pengetahuan usaha dan usaha terhambat dalam perkembangan kinerja usaha tersebut. Hal tersebut banyak didukung oleh penelitian yang sudah dilakukan sebelumnya seperti penelitian (Brouthers et al., 2014; Wiklund, 1999; Zahra, 1991; Zahra dan Covin, 1995) dimana perusahaan yang menerapkan orientasi kewirausahaan dengan baik akan memiliki kinerja usaha yang lebih baik.

Faktor kedua yang dianggap sangat penting untuk kinerja usaha yaitu orientasi pasar (Market Orientation). Orientasi pasar adalah salah satu tujuan utama para pemilikusaha UMKM untuk mengembangkan pengetahuannya didalam menerapkan berbagai strategi pemasaran agar dapat mengembangkan usaha yang sedang dijalankan (Slater dan Narver, 1994), maka strategi yang dimiliki harus dapat memuaskan pelanggan. Krena orientasi pasar adalah suatu hal yang mengutamakan kepuasan pelanggan dari kebutuhan dan keinginannya yang menjadikan target pasar (Blankson dan Cheng, 2005). Orientasi pasar ini memiliki tiga komponen perilaku yaitu orientasi pelanggan, orientasi pesaing dan koordinasi interfungsional. Orientasi pelanggan merupakan suatu pemahaman atau pengetahuan tentang target pembelianyang memiliki nilai lebih untuk membrikan kepuasan pelanggan. Orientasi pesaing adalah pemahaman atau pengetahuan tentang kekuatan atau kelemahan yang dimiliki oleh pesaing agar dapat mengetahui bagian strategi pemasaran pesaing kita. Sedangkan koordinasi interfungsional adalah pmahaman atau pengetahuantentang informasi pelanggan serta pesaing dan terdiri dari usaha bisnis yang terkoordinasi. Lebih rinci dijelaskan bahwa orientasi pelanggan diartikan sebagai pemahaman yang memadai tentang target berpelanggan dengan tujuan agar dapat menciptakan nilai lebih bagi pembeli secara terus-menerus dan orientasi pesaing merupakan usaha yangsering dilihat sebagai usaha yang mempunyai strategi bagaimana dapat membagikan informasi mengenai pesaing-pesaing yang ada (Narver dan Slater, 1990). Oleh karena itu, ada beberapa faktor yang dapat mencapai tujuan tersebut yaitu dapat menghasilkan kinerja dengan menciptakan nilai produk unggul bagi pelanggan dengan berfokus kepada kebutuhan pelanggan dan keuntungan jangka panjang, perusahaan harus mampu untuk terus berinovasi dalam setiap aspek dari operasional bisnis untuk dapat bersaing, mempertahankan nilai pelanggan, dan tetap bertahan di pasar yang kompetitif.

Tetapi orientasi pasar terhadap kinerja bisnis memiliki beberapa kendala.Ada beberapa kelemahan jika serorang pengusaha tidak menerapkan orientasi pasar terhadap kinerja bisnis. Pertama, pelanggan tidak selalu menyadari apa yang selalu menjadi kbutuhannya, terutama kebutuhan di waktu yang akan datang sehingga perlu diberi arahan atau pandangan sebelum pesaing lain mengambilnya (Gibson, et al., 1997) mengatakan bahwa perusahaan yangakan menjadi pemenang ialah perusahaan yang berada di posisi paling depan. Kedua, meskipun kebutuhan tersebut sudah dapat diidentifikasi oleh pelanggan, mereka sendiri tidak mampu menentukan cara terbaik untuk memenuhi kepuasan suatu pelanggan (Gabel, 1995). Hal tersebut sesuai dengan penelitian yang sudah dilakukan dimana hasilnya menunjukan bahwa adanya suatu hubungan dan pengaruh antara orientasi pasar dengan kinerja usaha. (Pelham dan Wilson, 1996) mengidentifikasi bahwa tingkat tinggi orientasi pasar menawarkan perusahaan yang kecil dengan sumber yang kuat dari keunggulan kompetitif dan kelangsungan hidup kinerja. (Baker dan Sinkula, 2009) mengatakan bahwa adanya 
suatu hubungan positif yang signifikan antara orientasi pasar dan profitabilitas dalam konteks usahakecil. (Verhess dan Meulenberg, 2004) mengungkapkan bahwa intelijen pasar terhadap pelanggan berhubungan positif dengan kinerja perusahaan di perusahaan kecil.Dengan demikian pemilik suatu usaha kuliner harus dapat menerapkan dan memahami orientasi kewirausahaan dan orientasi pasar untuk dapat menciptakan kinerja usaha yang maksimal sehingga dapat bersaing dengan kompetitor yang lain.

\section{KAJIAN TEORI}

Menurut pendapat (Simamora, 2001) kinerja merupakan sebuah pencapaian persyaratanpersyaratan pekerjaan tertentu yang secara langsung dapat tercermin dari nilai output yang dihasilkan baik dari jumlah maupun kualitas. Sedangkan menurut (Veithzal Rivaidalam Sumiati, 2015) kinerja perusahaan adalah keberhasilan seseorang secara keseluruhan dalam waktu tertentu didalam melaksanakan tugas dibandingkan dengan berbagai kemungkinan seperti standar hasil kerja, target yang telah ditentukan terlebih dahulu dan sudah disepakati bersama. Kinerja usaha pada Usaha Mikro Kecil dan Menengah (UMKM) sangat dipengaruhi oleh keunggulan kompetitif. Keunggulan kompetitif adalah kemampuan yang dimiliki melalui karakteristik dan sumber daya disuatu perusahaan untuk memiliki kinerja yang lebih tinggi dibandingkan dengan perusahaan lainnya pada industri atau pasar yang sama.

Menurut pendapat (Wiklund dan Sherperd, 2005) menemukan orientasi kewirausahaan memiliki pengaruh yang signifikan terhadap kinerja usaha. Penelitian yang dilakukan oleh (Keh et al., 2007) menunjukan bahwa tingkat orientasi kewirausahaan memiliki efek langsung dan tidak langsung pada kinerja perusahaan. Sejumlah penelitian juga telah menunjukan bahwa orientasi kewirausahaan secara langsung maupun tidak langsung memiliki hubungan positif dan pengaruh signifikan terhadap kinerja perusahaan. (Rauch et al., 2009; Zahra dan Garvis, 2000; Wiklund dan Shepherd, 2005).

Orientasi kewirausahaan adalah karakteristik dan nilai yang dianut oleh wirausaha itu sendiri yang merupakan sifat pantang menyerah, berani mengambil resiko, kecepatan dan fleksibelitas. (Debbie Liao dan Philip Sohmen, 2001). (Lumpkin dan Dess, 1996) mempunyai pendapatbahwa orientasi kewirausahaan adalah sebagai tingkat keberanian seorang wirausaha untuk menjadi yang pertama dalam inovasi produk pasar, melakukan tindakan proaktif dan kemandirian dalam menjalankan usaha dan berani mengambil resiko. Orientasi kewirausahaan dapat diukur dengan 3 dimensi yaitu inovasi, proaktif dan mengambil resiko. (Matsuno et al., 2002; Miller, 1983).

(Pelham dan Wilson, 1996) mengidentifikasi bahwa tingkat tinggi orientasi pasar menawarkan perusahaan kecil sumber yang kuat dari keunggulan kompetitif dan kelangsungan hidup kinerja. (Baker dan Sinkula, 2009) menemukan bahwa ada hubungan positif yang signifikan antara orientasi pasar dan profitabilitas dalam konteks usaha kecil. Orientasi pasar adalahsebuah proses yang menghasilkan dan memberikan informasi mengenai pasar dengan tujuan menciptakan superior value atau nilai lebih untuk konsumen. (Lukas dan Ferrel, 2000). Sedangkan menurut (Narver dan Slater, 1990) berpendapat bahwa orientasi pasar sebagai budaya organisasi yang paling efektif dalam menciptakan perilaku penting untuk menciptakan nilai yang unggul bagi pembeli serta kinerja dalam bisnis. Orientasi pasar terdiri dari 3 komponen perilaku yaitu orientasi pelanggan, orientasi pesaing dan koordinasi antar fungsi.

\section{Definisi Konseptual Variabel}

Orientasi Kewirausahaan. Orientasi kewirausahaan adalah sikap yang menunjukan perilaku pemilik usaha untuk mengambil suatu resiko bisnis (berani mengambil resiko), mendukung dilakukannya perubahan dan inovasi untuk mendapatkan keuntungan yang kompetitif (inovasi) dan mampubersaing secara agresif dengan kompetitornya. (Covin et al, 2006). 
Orientasi Pasar. Orientasi pasar adalah budaya organisasi yang paling efektif dan efisien dalam menciptakan perilaku yang diperlukan untuk penciptaan nilai unggul bagi pelanggansehingga dapat menghasilkan kinerja bisnis yang unggul secara berkesinambungan. Orientasi kewirausahaan mencerminkan sejauh mana perusahaan mengidentifikasi dan mengeksploitasi peluang yang belum dimanfaatkan sebagai prinsip pengorganisasian dalam perusahaan. (Baker dan Sinkula, 2009).

Kinerja. Kinerja adalah suatu pencapaian persyaratan pekerjaan tertentu yang secara langsung dapat tercermin dari nilai - nilai output yang dihasilkan baik dari jumlah maupun kualitas. (Simamora, 2001).

Berdasarkan uraian-uraian diatas, maka hipotesis pada penelitian ini dapat dilihat pada Gambar 1

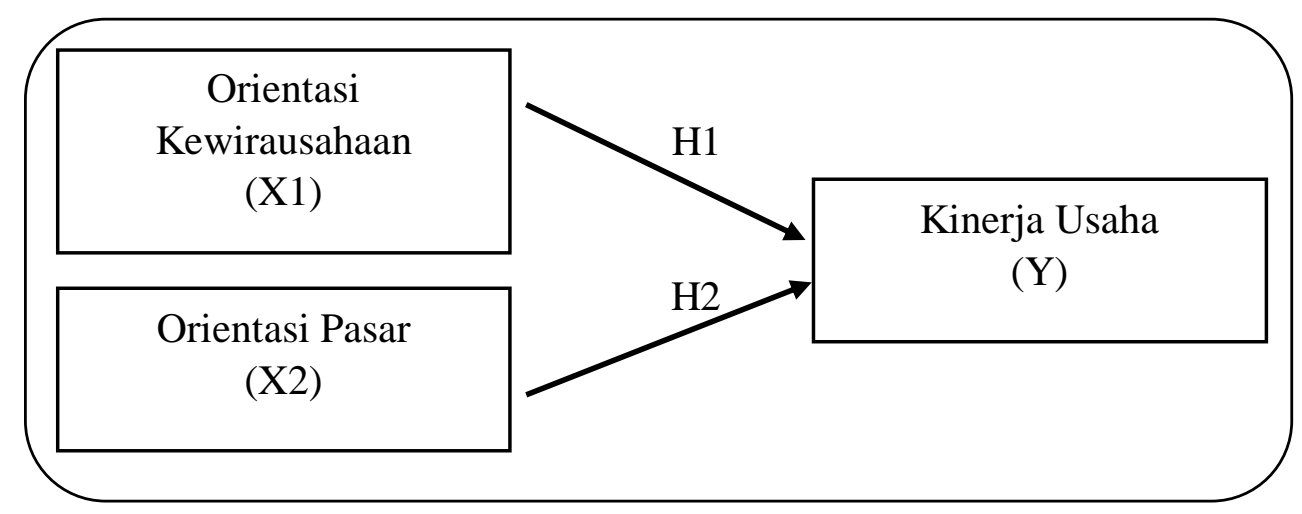

Gambar 1. Kerangka Hipotesis

Berdasarkan Gambar 1 tersebut, maka hipotesis dalam penelitian ini sebagai berikut:

H1: Terdapat pengaruh signifikan dan hubungan positif orientasi kewirausahaan terhadap kinerja Usaha Mikro Kecil dan Menengah pada bidang kuliner di Pasar Lama Tangerang.

H2: Terdapat pengaruh signifikan dan hubungan positif orientasi pasar terhadap kinerja Usaha Mikro Kecil dan Menengah pada bidang kuliner di Pasar Lama Tangerang.

\section{METODOLOGI}

Desain penelitian merupakan suatu rencana penelitian yang dibuat secara sistematis, sehingga penelitian dapat memperoleh jawaban terhadap pertanyaan-pertanyaan yang tepat dalam penelitian. (Setiadi, 2007). Menurut pendapat (Sugiyono, 2016) desain penelitian adalah sebuah cara ilmiah untuk mendapatkan data dengan tujuan dan kegunaan tertentu. Jenis penelitian terbagi menjadi dua jenis yaitu penelitian kualitatif dan kuantitatif. Dalam penelitian ini, peneliti menggunakan jenis penelitian kuantitatif. Penelitian kuantitatif merupakan sebuah pengukurandata kuantitatif dan statistik objektif dengan menggunakan perhitungan ilmiah yang berasal dari sampel orang-orang yang diminta untuk menjawab beberapa pertanyaan survei untuk dapat menentukan frekuensi dan presentasi tanggapan orang-orang tersebut. Menurut (Kasiram, 2008) pengertian penelitian kuantitatif adalah metode penelitian yang menggunakan angka sebagai data-data untuk menganalisis dan melakukan kajian penelitian, terutama mengenai sesuatu yang sudah diteliti. Penelitian ini menggunakan desain penelitian konklusif. Penelitian konklusif adalah sebuah penelitian yang di lakukan dengan tujuan untuk membantu pembuat keputusan dalam menentukan sebuah keputusan, memilih alternatif terbaik yang dapat diambil pada sebuah situasi tertentu. Tujuan penelitian konklusif yaitu untuk dapat menguji hipotesis dan menguji pengaruh variabel satu dengan variabel yang lainnya. 
Pengertian penelitian kausal adalah metode penelitian yang dapat menguji secara benar dan tepat dalam hipotesis menyangkut hubungan kausal (sebab akibat). (Gay, 1981). Menurut pendapat (Malhotra, 2004), penelitian konklusif adalah penelitian yang menggambarkan untuk mengambil sebuah keputusan dalam menentukan, evaluasi, dan memilih rangkaian tindakan yang terbaik untuk diambildalam situasi yang ada. Desain penelitian konklusif terbagi menjadi dua yaitu metode deskriptif dan kausal. Penelitian ini menggunakan metode kausal. Metode kausal adalah hubungan yang mempunyai sifat sebab akibat, metode kasualmemiliki variabel independen (mempengaruhi) dan variabel dependen (dipengaruhi). Maka dari itu penelitian berfokus pada pengaruh penggunaan media gambar sebagai variabel independen terhadap hasil belajar sebagai variabel dependen. (Sugiyono, 2012). Penelitian kausal memiliki karakteristik utama yaitu adanya pengaruh dan hubungan variabel independen terhadap variabel dependen.

Hasil Analisis Model Struktural. Analisis model structural menggunakan model boostrapping pada gambar dibawah ini

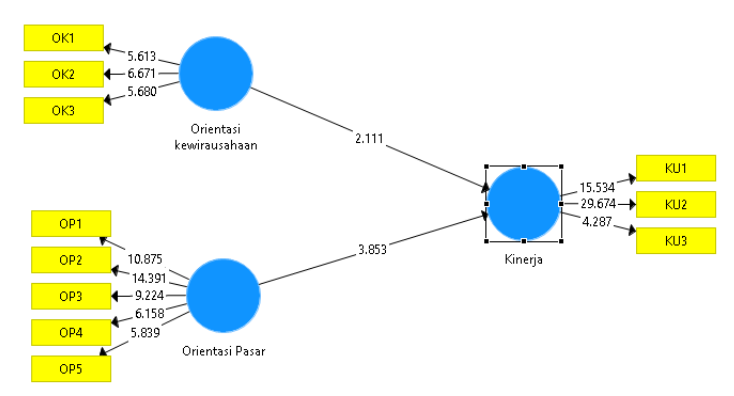

Gambar 2. Hasil Bootstrapping

Hasil pengujian koefisien determinasi yang ditampilkan pada tabel 4.9 diatas, maka nilai $R$ square adalah sebesar 0,270 yang berarti besarnya pengaruh $\mathrm{X} 1$ dan $\mathrm{X} 2$ terhadap $\mathrm{Y}$ adalah sebesar $27 \%$ dan dapat dikatakan koefisien determinasi $\left(\mathrm{R}^{2}\right)$ memiliki pengaruh yang lemah. Sedangkan $72 \%$ kinerja dipengaruhi oleh variabel lain yang tidak terdapat dalam penelitian ini. Sedangkan hasil path coefficients yang dihasilkan, maka dapat diperoleh persamaan dalam penelitian ini yaitu $\mathrm{KU}=$ 0,244OK + 0,386OP. Berdasarkan persamaan tersebut maka dapat disimpulkan bahwa hubungan variabel orientasi kewirausahaan terhadap kinerja memiliki hubungan yang positif dan variabel orientasi pasar terhadap kinerja juga memiliki hubungan yang positif.

Hasil Pengujian Goodness of Fit (GoF). Berikut merupakan perhitungan nilai Goodness of Fit (GoF):

$$
\begin{aligned}
& \overline{A V E}=0,6076 \\
& \overline{R^{2}}=0,270 \\
& G O F=\sqrt{\overline{A V E} x \overline{R^{2}}} \\
& G O F=\sqrt{0,6076 \times 0,270} \\
& G O F=0,4050
\end{aligned}
$$

Berdasarkan hasil perhitungan Goodness of Fit (GoF) diatas, maka mendapatkan disimpulkan bahwa model yang digunakan didalam penelitian ini memiliki kecocokan model penelitian yang tergolong besar. 
Hasil Pengujian Hipotesis. Hasil pengujian variabel orientasi kewirausahaan terhadap kinerja Usaha Mikro Kecil dan Menengah, maka dapat dikatakan bahwa H1 tidak ditolak karena orientasi kewirausahaan memiliki nilai t-statistik sebesar 2,111 dan nilai p-values sebesar 0,035 atau 3,5\%. Nilait-statistik tersebut lebih besar dari pada batas nilai kriteria yaitu 1,96 dan nilai p-values lebih kecil dari 0,05 atau 5\%. Sehingga dapat disimpulkan bahwa variabel orientasi kewirausahaan dapat berpengaruh secara signifikan terhadap kinerja Usaha Mikro Kecil dan Menengah. Hasil pengujian variabel orientasi pasar terhadap kinerja Usaha Mikro Kecil dan Menengah, maka dapat dikatakan bahwa $\mathrm{H} 2$ tidak ditolak karena orientasi pasar memiliki nilai t-statistiksebesar 3,853 dan nilai pvalues sebesar 0,000 atau $0 \%$. Nilait-statistik tersebut lebih besar dari pada batas nilai kriteria yaitu 1,96 dan nilai p-values lebih kecil dari 0,05 atau 5\%. Sehingga dapat disimpulkan bahwa variabel orientasi pasar dapat berpengaruh secara signifikan terhadap kinerja Usaha Mikro Kecil dan Menengah.

\section{DISKUSI}

Hasil pengujian hipotesis yang pertama menunjukan bahwa orientasi kewirausahaan berpengaruh signifikan terhadap kinerja. Hal tersebut sangat sesuai dengan penelitian yang telah dilakukan oleh (Wiklund dan Shepherd, 2005; Smart dan Conant, 1994) dimana penelitian tersebut mengatakan bahwa orientasi kewirausahaan dan kinerja terkait secara signifikan. Hasil pengujian hipotesis yang kedua menunjukan bahwa orientasi pasar berpengaruh signifikan terhadap kinerja. Hal tersebut sesuai dengan penelitian (Baker dan Sinkula, 2009). (Narver dan Slater, 1990) yang menyatakan bahwa orientasi pasar memiliki pengaruh signifikan terhadap kinerja. Sehingga pemilik usaha harus dapat menerapkan orientasi pasar untuk dapat meningkatkan kinerja usaha.

\section{PENUTUP}

Orientasi kewirausahaan berpengaruh signifikan dan berhubungan positif terhadap kinerja Usaha Mikro Kecil dan Menengah pada indsutri kuliner di Pasar Lama Tangerang. Orientasi Pasar berpengaruh signifikan dan berhubungan positif terhadap kinerja Usaha Mikro Kecil dan Menengah pada indsutri kuliner di Pasar Lama Tangerang. Peneliti menyarankan pemilik Usaha Mikro Kecil dan Menengah pada indsutri kedai kopi untuk tetap menjaga penerapan orientasi kewirausahaan yang sudah baik dengan tetap memperkenalkan produk dan layanan yang baru untuk mencapai pertumbuhan perusahaan. Peneliti menyarankan pemilik Usaha Mikro Kecil dan Menengah pada indsutri kedai kopi untuk tetap menjaga penerapan orientasi pasar yang sudah baik dengan tetap melakukan kegiatan yang kompetitif dalam menciptakan kepuasan pelanggan untuk dapat meningkatkan kinerja usaha.

\section{DAFTAR PUSTAKA}

Alam, M.M., (2013), Effect of Market Orientation on Small Business Perormance in Small Town In Malaysia: An Emprical Study on Malaysian Small Firms, Journal of Strategic Marketing, Vol 1, No. 3.

Baker, W. E., and Sinkula, J. M. (2009). The complementary effects of market orientation and entrepreneurial orientation on profitability in small businesses. Journal of small business management, 47(4), 443-464.

Becherer, R. C., Helms, M. M., and McDonald, J. P. (2012). The effect of entrepreneurial marketing on outcome goals in SMEs. New England Journal of Entrepreneurship, 15(1), 7-18

Brouthers, K. D., Nakos, G., and Dimitratos, P. (2014). SME entrepreneurial orientation, international performance, and the moderating role of strategic alliances. Entrepreneurship Theory and Practice, 39(5), 1161-1187. 
Chen, S. C., and Quester, P. G. (2006). Modeling store loyalty: perceived value in market orientation practice. Journal of Services Marketing, 20(3), 188-198.

Cnnindonesia. Ekonomi. (2018) Kontribusi UMKM terhadap PDB tembus Lebih dari 60 persen (Retrieved From:

https://www.cnnindonesia.com/ekonomi/20161121122525-92-174080/kontribusi-umkmterhadap-pdb-tembus-lebih-dari-60-persen/11-09-2018)

Covin, J. G., and Slevin, D. P. (1989). Strategic management of small firms in hostile and benign environments. Strategic management journal, 10(1), 75-87.

Covin, J. G., Green, K. M., and Slevin, D. P. (2006). Strategic process effects on the entrepreneurial orientation-sales growth rate relationship. Entrepreneurship theory and practice, 30(1), 5781.

Craven, D. W., (2004). Pemasaran Strategis, Jakarta: Erlangga.

Djaali. (2008). Skala Likert. Jakarta: Pustaka Utama.

Elg, U. (2007). Market orientation processes in retailing: a cross-national study. European Journal of Marketing, 41(5/6), 568-589.

Elg, U., and Paavola, H. (2008). Market orientation of retail brands in the grocery chain: the role of supplier relationships. The International Review of Retail, Distribution and Consumer Research, 18(2), 221-233.

Fatmawati, R. A., Pradhanawati, A., dan Ngatno, N. (2016). Pengaruh Orientasi Pasar, Orientasi Kewirausahaan terhadap Keunggulan Bersaing dan Kinerja Pemasaran pada Warung Kucingan/angkringan di Kota Semarang. Jurnal Ilmu Administrasi Bisnis, 5(3), 351-362.

Ferdinand, A. (2000). Manajemen Pemasaran: Sebuah Pendekatan Stratejik. Research Paper Series, $1,1-55$.

Frese, M., Brantjes, A., and Hoorn, R. (2002). Psychological success factors of small scale businesses in Namibia: The roles of strategy process, entrepreneurial orientation and the environment. Journal of developmental Entrepreneurship, 7(3), 259-282.

Gathungu, J. M., Aiko, D. M., and Machuki, V. N. (2014). Entrepreneurial orientation, networking, external environment, and firm performance: A critical literature review. European Scientific Journal, ESJ, 10(7).

Ghozali, I. (2008). Structural equation modeling: Metode alternatif dengan partial least square (pls). Badan Penerbit Universitas Diponegoro.

Ginsberg, A. (2011). Measuring Changes in Entrepreneurial Orien-tation Following Industry Deregulation: The Development ofa Diagnostic Instrument. M arietta, GA: Proceedingsof the International Council of Small Business, 57.

Hair, J. F., Ringle, C. M., and Sarstedt, M. (2011). PLS-SEM: Indeed a silver bullet. Journal of Marketing theory and Practice, 19(2), 139-152.

Hanifah, H. (2012). Pengaruh orientasi kewirausahaan, budya organisasi dan strategi bisnis terhadap kinerja perusahaan. In seminar nasional dan call for papers. Fakultas ekonomi unisbank.

Henseler, J., Ringle, C. M., and Sinkovics, R. R. (2009). The use of partial least squares path modeling in international marketing. In New challenges to international marketing (pp. 277-319). Emerald Group Publishing Limited.

Hooley, G. J., Greenley, G. E., Cadogan, J. W., and Fahy, J. (2005). The performance impact of marketing resources. Journal of business research, 58(1), 18-27.

Howell, J. M., and Avolio, B. J. (1993). Transformational leadership, transactional leadership, locus of control, and support for innovation: Key predictors of consolidated-business-unit performance. Journal of applied psychology, 78(6), 891.

Hult, G. T. M., and Ketchen Jr, D. J. (2001). Does market orientation matter?: A test of the relationship between positional advantage and performance. Strategic management journal, 22(9), 899-906.

Hussein, A. S. (2015). Penelitian bisnis dan manajemen menggunakan partial least squares (PLS) dengan smartPLS 3.0. Modul Ajar. 
Kajalo, S., and Lindblom, A. (2015). Market orientation, entrepreneurial orientation and business performance among small retailers. International Journal of Retail \& Distribution Management, 43(7), 580-596.

Kara, A., Spillan, J. E., and DeShields Jr, O. W. (2005). The effect of a market orientation on business performance: A study of small-sized service retailers using MARKOR scale. Journal of small business management, 43(2), 105-118.

Keh, H. T., Nguyen, T. T. M., and Ng, H. P. (2007). The effects of entrepreneurial orientation and marketing information on the performance of SMEs. Journal of business venturing, 22(4), 592-611.

Kirca, A. H., Jayachandran, S., and Bearden, W. O. (2005). Market orientation: A meta-analytic review and assessment of its antecedents and impact on performance. Journal of marketing, 69(2), 24-41.

Kohli, A. K., and Jaworski, B. J. (1990). Market orientation: the construct, research propositions, and managerial implications. The Journal of Marketing, 1-18.

Kohli, A. K., Jaworski, B. J., and Kumar, A. (1993). MARKOR: a measure of market orientation. Journal of Marketing research, 467-477.

Kozlowski, S. W., and Doherty, M. L. (1989). Integration of climate and leadership: Examination of a neglected issue. Journal of applied psychology, 74(4), 546.

Kraus, S. (2013). The role of entrepreneurial orientation in service firms: empirical evidence from Austria. The Service Industries Journal, 33(5), 427-444.

Kreiser, P. M., Marino, L. D., and Weaver, K. M. (2002). Assessing the psychometric properties of the entrepreneurial orientation scale: A multi-country analysis. Entrepreneurship theory and practice, 26(4), 71-93.

Lee, T. K., and Chu, W. (2011). Entrepreneurial orientation and competitive advantage: The mediation of resource value and rareness. African Journal of Business Management, 5(33), 12797-12809.

Liao, D., and Sohmen, P. (2001). The development of modern entrepreneurship in China. Stanford Journal of East Asian Affairs, 1(1), 27-33.

Lings, I. N., and Greenley, G. E. (2005). Measuring internal market orientation. Journal of Service Research, 7(3), 290-305.

Lings, I. N., and Greenley, G. E. (2009). The impact of internal and external market orientations on firm performance. Journal of Strategic Marketing, 17(1), 41-53.

Lukas, B. A., and Ferrell, O. C. (2000). The effect of market orientation on product innovation. Journal of the academy of marketing science, 28(2), 239-247.

Lumpkin, G. T., and Dess, G. G. (1996). Clarifying the entrepreneurial orientation construct and linking it to performance. Academy of management Review, 21(1), 135-172.

Lumpkin, G. T., and Dess, G. G. (2001). Linking two dimensions of entrepreneurial orientation to firm performance: The moderating role of environment and industry life cycle. Journal of business venturing, 16(5), 429-451

Lumpkin, G.T., and Dess, G. G. (2005). The role of entrepreneurial orientation in stimulating effective corporate entrepreneurship. Academy of Management Perspectives, 19(1), 147-156.

Maholtra, N. K. (2010). Essentials Of Marketing Research. England: Pearson Educated Limited.

Maholtra, N. K. (2015). Essentials Of Marketing Research. England: Pearson Educated Limited.

Malhotra, Naresh K (2009). Marketing research : an applied orientation (6th ed., Global ed). Pearson Education, Upper Saddle River, N.J. ; Harlow

Matsuno, K., Mentzer, J. T., and Özsomer, A. (2002). The effects of entrepreneurial proclivity and market orientation on business performance. Journal of marketing, 66(3), 18-32.

Maydeu-Olivares, A., and Lado, N. (2008). Market orientation and business economic performance: A mediated model. International Journal of Service Industry Management, 14(3), 284-309. 
Megicks, P., and Warnaby, G. (2008). Market orientation and performance in small independent retailers in the UK. The International Review of Retail, Distribution and Consumer Research, $18(1), 105-119$.

Messaghem, K. (2003). "Strategic Entrepreneurship and Managerial Activities in SMEs," International Small Business Journal, Volume 21, Number 2, 197-212.

Miller, D. (1983). The correlates of entrepreneurship in three types of firms. Management science, 29(7), 770-791.

Moullin, M. (2007). Performance measurement definitions: Linking performance measurement and organisational excellence. International journal of health care quality assurance, 20(3), 181183.

Narver, J. C., and Slater, S. F. (1990). The effect of a market orientation on business profitability. The Journal of marketing, 20-35.

Nuvriasari, A., Wicakson, G., dan Sumiyarsih, S. (2015). Peran orientasi pasar, orientasi kewirausahaan dan strategi bersaing terhadap peningkatan kinerja UKM. ekuitas (Jurnal Ekonomi dan Keuangan), 19(2), 241-259.

Ottencoffee. Sejarah first second and third wave coffee. Diperoleh 3 September 2018, dari https://majalah.ottencoffee.co.id/sejarah-first-second-and-third-wave-coffee/

Panigyrakis, G. G., and Theodoridis, P. K. (2007). Market orientation and performance: An empirical investigation in the retail industry in Greece. Journal of Retailing and Consumer Services, 14(2), 137-149.

Patel, P. C., and D'Souza, R. R. (2009). Leveraging entrepreneurial orientation to enhance SME export performance. An Office of Advocacy Working Paper, 337, 1-32.

Pelham, A. M. (2000). Market orientation and other potential influences on performance in small and medium-sized manufacturing firms. Journal of small business management, 38(1), 48-67.

Pelham, A. M., and Wilson, D. T. (1996). A longitudinal study of the impact of market structure, firm structure, strategy, and market orientation culture on dimensions of small-firm performance. Journal of the academy of marketing science, 24(1), 27-43.

Rauch, A., Wiklund, J., Lumpkin, G. T., and Frese, M. (2009). Entrepreneurial orientation and business performance: An assessment of past research and suggestions for the future. Entrepreneurship theory and practice, 33(3), 761-787.

Santos, J. B., and Brito, L. A. L. (2012). Toward a subjective measurement model for firm performance. BAR-Brazilian Administration Review, 9(SPE), 95-117.

Sekaran, U. (2006). Research Methods for Business Buku2. Jakarta: Salemba Empat.

Simamora, H. Manajemen Sumber Daya Manusia, 2001. Yogyakarta: Bagian Penerbitan Sekolah Tinggi Ilmu Ekonomi YKPN.

Smart, D. T., and Conant, J. S. (1994). Entrepreneurial orientation, distinctive marketing competencies and organizational performance. Journal of applied business research, 10, 2828.

Soehartono, I. (2004). Metode Penelitian Sosial. Bandung: PT.Remaja rosdakarya.

Sternquist, B., Huang, Y., and Chen, Z. (2010). Predicting market orientation: Chinese retailers in a transitional economy. International Journal of Retail \& Distribution Management, 38(5), 360-378.

Sternquist, B., Runyan, R. C., and Chen, Z. (2008). The use of buying committees by Chinese retailers: The effects of environment and strategy upon structure. Journal of Retailing and Consumer Services, 15(2), 93-103.

Sugiyono, (2008). Metode Penelitian Bisnis. Bandung: Alfabeta.

Sugiyono. (2001). Perilaku pembelian konsumen dan komunikasi pemasaran. Bandung: Rosda.

Sugiyono. (2005). Memahami Penelitian Kualitatif. Bandung: ALFABET.

Sumiati, S. (2015). Pengaruh Strategi Orientasi Wirausaha dan Orientasi Pasar Pengaruhnya Terhadap Kinerja Perusahaan UMKM di Kota Surabaya. JMM17: Jurnal Ilmu Ekonomi dan Manajemen, 2(01). 
Tenenhaus, Michel, Vincenzo Esposito Vinzi, Yves-Marie Chatelin, and Carlo Lauro. "PLS path modeling." Computational statistics \& data analysis 48, no. 1 (2005): 159-205.

Uncles, M. (2000). Market orientation. Australian Journal of Management, 25(2).

Verhees, F. J., and Meulenberg, M. T. (2004). Market orientation, innovativeness, product innovation, and performance in small firms. Journal of small business management, 42(2), 134-154.

Wahyono.,(2002). Orientasi dan inovasi: Pengaruhnya terhadap Kinerja Pemasaran. Jurnal Sains Pemasaran Indonesia. Vol 1 No. 1 Mei 2002 H. 23-40

Wetzels, M., Odekerken-Schröder, G., and Van Oppen, C. (2009). Using PLS path modeling for assessing hierarchical construct models: Guidelines and empirical illustration. MIS quarterly, 177-195.

Wikipedia. (2016) Keunggulan kompetitif.

(Retrieved From: https://id.wikipedia.org/wiki/Keunggulan_kompetitif/01-04-2018)

Wiklund, J. (1999). The sustainability of the entrepreneurial orientation-performance relationship. Entrepreneurship theory and practice, 24(1), 37-48.

Wiklund, J., and Shepherd, D. (2005). Entrepreneurial orientation and small business performance: a configurational approach. Journal of business venturing, 20(1), 71-91.

Zahra, S. A. (1991). Predictors and financial outcomes of corporate entrepreneurship: An exploratory study. Journal of business venturing, 6(4), 259-285.

Zahra, S. A., and Covin, J. G. (1995). Contextual influences on the corporate entrepreneurshipperformance relationship: A longitudinal analysis. Journal of business venturing, 10(1), 4358.

Zahra, S. A., and Garvis, D. M. (2000). International corporate entrepreneurship and firm performance: The moderating effect of international environmental hostility. Journal of business venturing, 15(5-6), 469-492.

Zhou, K. Z., Brown, J. R., \& Dev, C. S. (2009). Market orientation, competitive advantage, and performance: A demand-based perspective. Journal of business research, 62(11), 1063-1070. 